\title{
The association of plasma biomarkers with computed tomography-assessed emphysema phenotypes
}

Brendan J Carolan ${ }^{1,2^{*}}$, Grant Hughes ${ }^{3}$, Jarrett Morrow ${ }^{4}$, Craig P Hersh ${ }^{4}$, Wanda K O'Neal ${ }^{5}$, Stephen Rennard ${ }^{6}$, Sreekumar G Pillai ${ }^{7}, 12$, Paula Belloni ${ }^{8,12}$, Debra A Cockayne ${ }^{9}$, Alejandro P Comellas ${ }^{10}$, Meilan Han ${ }^{11}$, Rachel L Zemans ${ }^{1,2}$, Katerina Kechris ${ }^{3}$ and Russell P Bowler ${ }^{1,2}$

\begin{abstract}
Rationale: Chronic obstructive pulmonary disease (COPD) is a phenotypically heterogeneous disease. In COPD, the presence of emphysema is associated with increased mortality and risk of lung cancer. High resolution computed tomography (HRCT) scans are useful in quantifying emphysema but are associated with radiation exposure and high incidence of false positive findings (i.e., nodules). Using a comprehensive biomarker panel, we sought to determine if there was a peripheral blood biomarker signature of emphysema.

Methods: 114 plasma biomarkers were measured using a custom assay in 588 individuals enrolled in the COPDGene study. Quantitative emphysema measurements included percent low lung attenuation (\%LAA) $\leq-950$ $\mathrm{HU}, \leq-910 \mathrm{HU}$ and mean lung attenuation at the $15^{\text {th }}$ percentile on lung attenuation curve (LP15A). Multiple regression analysis was performed to determine plasma biomarkers associated with emphysema independent of covariates age, gender, smoking status, body mass index and $\mathrm{FEV}_{1}$. The findings were subsequently validated using baseline blood samples from a separate cohort of 388 subjects enrolled in the Treatment of Emphysema with a Selective Retinoid Agonist (TESRA) study.

Results: Regression analysis identified multiple biomarkers associated with CT-assessed emphysema in COPDGene, including advanced glycosylation end-products receptor (AGER or RAGE, $p<0.001$ ), intercellular adhesion molecule 1 (ICAM, $p<0.001$ ), and chemokine ligand 20 (CCL20, $p<0.001$ ). Validation in the TESRA cohort revealed significant associations with RAGE, ICAM1, and CCL20 with radiologic emphysema ( $p<0.001$ after meta-analysis). Other biomarkers that were associated with emphysema include CDH1, CDH 13 and SERPINA7, but were not available for validation in the TESRA study. Receiver operating characteristics analysis demonstrated a benefit of adding a biomarker panel to clinical covariates for detecting emphysema, especially in those without severe airflow limitation (AUC 0.85).

Conclusions: Our findings, suggest that a panel of blood biomarkers including SRAGE, ICAM1 and CCL20 may serve as a useful surrogate measure of emphysema, and when combined with clinical covariates, may be useful clinically in predicting the presence of emphysema compared to just using covariates alone, especially in those with less severe COPD. Ultimately biomarkers may shed light on disease pathogenesis, providing targets for new treatments.
\end{abstract}

Keywords: COPD, Biomarkers, RAGE, ICAM1, CCL20, Emphysema

\footnotetext{
* Correspondence: CarolanB@NJHealth.org

'Department of Medicine, National Jewish Health, 1400 Jackson St, Denver,

CO 80206, USA

${ }^{2}$ Department of Medicine, University of Colorado School of Medicine, Aurora,

CO, USA

Full list of author information is available at the end of the article
}

\section{Biomed Central}

(c) 2014 Carolan et al.; licensee BioMed Central Ltd. This is an Open Access article distributed under the terms of the Creative Commons Attribution License (http://creativecommons.org/licenses/by/4.0), which permits unrestricted use, distribution, and reproduction in any medium, provided the original work is properly credited. The Creative Commons Public Domain Dedication waiver (http://creativecommons.org/publicdomain/zero/1.0/) applies to the data made available in this article, unless otherwise stated. 


\section{Introduction}

Chronic obstructive pulmonary disease (COPD) is a phenotypically heterogeneous condition characterized by airflow limitation that is not fully reversible [1]. Some, but not all, COPD subjects have emphysema, i.e., airspace enlargement distal to the terminal bronchioles [2]. Determining the presence of emphysema is important, as it has been independently associated with increased respiratory symptoms, more rapid decline in lung function, increased risk of lung cancer, higher rates of cardiovascular disease and increased mortality risk [3-6]. Surprisingly, there are some subjects with significant smoking history that have emphysema, but no airflow limitation [7]. Understanding the molecular signatures underlying emphysema may shed light on the pathogenesis of emphysema and its systemic complications.

The best current non-invasive method of detecting emphysema is high-resolution computed tomography (HRCT) $[8,9]$. The drawbacks to HRCT include cost, radiation exposure, and a high rate of false positive clinical significant findings (e.g. benign nodules); however, HRCT can provide significant information relevant to lung pathology. For instance, lung attenuation area (LAA) at -950 or -910 Hounsfield units (HU) and the mean lung attenuation value at the $15^{\text {th }}$ percentile (LP15A) on the lung attenuation curve are density-based measurements that correlate with emphysema $[8,10,11]$. Although the optimal method and normal values for describing radiologic emphysema have not been fully validated, it has been shown that control smokers without COPD have percent $\mathrm{LAA} \leq \mathbf{- 9 5 0}$ HU of $<5 \%$ [9].

The first reported blood biomarker of emphysema was $\alpha 1$-antitrypsin (AAT); however, AAT deficiency accounts for only $1-2 \%$ of COPD [12]. Another recently reported independent biomarker of emphysema is soluble RAGE or advanced glycosylation end product receptor (AGER) [13]. Peripheral blood adiponectin and bronchoalveolar lavage fluid eotaxin levels have also correlated with radiologic emphysema $[14,15]$. There are other reports of peripheral blood biomarkers of airflow limitation such as interleukin6 , surfactant protein D and C-reactive protein $[16,17]$. Therefore, the presence of systemic biomarkers in peripheral blood, which can be easily measured and offer information regarding COPD phenotypes, may provide another method of significant value in diagnosing and managing individuals with emphysema [18]. In addition, a biomarker signature of emphysematous phenotypes may provide insight to the pathogenesis of disease. Limitations of some previous emphysema biomarker studies include small sample size and lack of replication. With this in mind, using one of the largest studies to date, we sought to determine a peripheral blood biomarker signature of emphysema, independent of other clinical variables, in current and former cigarette smokers with normal lung function and with COPD, and relate the biomarker signature to different methods of defining radiologic emphysema. Key findings were validated in an independent COPD cohort.

\section{Methods}

\section{Study population}

COPDGene is a multi-centered study of the genetic epidemiology of COPD that enrolled 10,192 non-Hispanic White and African-American individuals, aged 45-80 years old with at least a 10 pack-year history of smoking, who had not had an exacerbation of COPD for at least the previous 30 days. Additional information on the COPDGene study and the collection of clinical data has been described previously [19]. 1839 COPDGene subjects (1599 non-Hispanic White (NHW) and 240 nonHispanic Black) had fresh frozen plasma collected using a p100 tube (BD) at five COPDGene sites (National Jewish Health ( $\mathrm{N}=916)$, University of Iowa $(\mathrm{N}=670)$, HarborUCLA Medical Center $(\mathrm{N}=202)$, Temple University $(\mathrm{N}=36)$, and Baylor Medical Center $(\mathrm{N}=15))$. From this cohort a subset of 602 NHW subjects (no non-Hispanic Black subjects included due to limited numbers) were selected for a comprehensive biomarker study with an attempt to obtain a range of GOLD stages and match groups as closely as possible based on age, gender and smoking history. Of the 602 subjects, 588 subjects had quantitative HRCT measurements available. The institutional review boards of participating institutions approved the study (Additional file 1: Table S1).

A separate validation cohort of 388 individuals (all former smokers with COPD) was obtained from the Treatment of Emphysema with a Selective Retinoid Agonist (TESRA) study. TESRA was a multi-centered randomized controlled trial assessing the safety and efficacy of palovarotene in exsmokers with COPD. Only baseline samples before treatment were used for biomarker determination. Emphysema was quantitatively assessed by low dose spiral CT in the TESRA cohort. Additional information on the TESRA study has been described previously [20].

\section{Clinical data and definitions}

COPD was defined as post bronchodilator ratio of forced expiratory volume in the first second $\left(\mathrm{FEV}_{1}\right)$ to forced vital capacity (FVC) $<0.70$. Current or ex-smokers without spirometric evidence of airflow obstruction $\left(\mathrm{FEV}_{1} / \mathrm{FVC} \geq 0.70\right)$ were classified as controls [1].

COPDGene study patients underwent whole lung volumetric multi-detector computed tomography $(\mathrm{CT})$ as previously described $[19,21]$. Quantitative analysis of lung density was performed using the Slicer software package (http://www.slicer.org). Emphysema was primarily quantified by the percent of lung voxels (\%LAA) $\leq-950 \mathrm{HU}$ on the inspiratory images of CT scans for the whole lung. Emphysema was additionally quantified by percent of lung 
voxels $(\% \mathrm{LAA}) \leq-910 \mathrm{HU}$ on inspiratory $\mathrm{CT}$ scans and as mean lung attenuation at the $15^{\text {th }}$ percentile on lung volume-adjusted attenuation curve (LP15A). In the TESRA cohort emphysema was quantified as \%LAA $\leq-910 \mathrm{HU}$ and LP15A on HRCT scans [20]. Densiometric analyses of the HRCTs were completed in a central lab (BioClinica, Leiden, The Netherlands) using PulmoCMS software (Medis specials, Leiden, The Netherlands). The study design and clinical outcomes have been previously reported $[13,20]$.

\section{Biomarker selection and measurement}

For the COPDGene cohort, 114 candidate biomarkers were selected based on a review of the literature and previously reported pilot work from the BIOSPIR group [22]. Biomarker levels were determined using a custom 15-panel assay created by Myriad-RBM (Austin, TX) multiplex technology. Blood samples were drawn from non-fasting individuals. Approximately $8.5 \mathrm{~mL}$ of blood was withdrawn from the ante-cubital vein into a sterile $13 \times 1000 \mathrm{~mm}$ P100 Blood Collection Tube (BD, New Jersey, USA). The sample was immediately centrifuged at $2500 \times \mathrm{g}$, 20 minutes at room temperature. Aliquots in $500 \mu \mathrm{L}$ tubes were stored at $-80^{\circ} \mathrm{C}$ until analyzed. In the TESRA cohort, 111 similarly chosen protein biomarkers were measured in ethylenediamine-tetraacetic acid (EDTA) plasma in duplicate at Rules Based Medicine (Austin, TX) and Quest Diagnostics (Valencia, CA). A full list of biomarkers analyzed in the TESRA study has been published [13]

\section{Statistical analysis}

Differences in demographic characteristics of study subjects were analyzed using a $t$-test for continuous variables and a Chi-squared test for categorical variables. Emphysema severity was classified as none, mild, moderate and severe. For \%LAA $\leq-950 \mathrm{HU}$ the cutoffs were $<5 \%, 5-<10 \%, 10-<20 \%$ and $\geq 20 \%$, respectively, while for \%LAA $\leq-910 \mathrm{HU}$ the cutoffs were $<35 \%, 35-<$ $45 \%, 45-<55 \%$ and $\geq 55 \%$, respectively. Cutoffs were based on mean values from COPDGene studies and balancing the sample size in each group [9].

Biomarkers $(n=17)$ with $>10 \%$ and $<95 \%$ of values below the lower limit of quantitation (LLOQ) for that particular biomarker were transformed into binary variables (present or absent). Biomarkers $(\mathrm{n}=16)$ with $>95 \%$ values below LLOQ were excluded from the analysis. For regression analysis, the remaining biomarker levels $(n=81)$ underwent an empirical normal quantile transformation projecting the ranks onto an inverse normal distribution so that they resemble a normal distribution and allow comparison of biomarkers at different concentrations. Nontransformed biomarker levels are also presented (Additional file 1: Table S3). Collinearity among biomarkers and covariates was assessed using Pearson correlation. Collinearity
$(\mathrm{R}>0.6)$ was observed between proinsulin intact (INS intact) and proinsulin total (INS total) so INS intact was removed from the analysis. Also, brain derived neurotropic factor (BDNF) was removed, as it was collinear with angiopoietin 1, CCL5 (T cell specific protein RANTES), epithelial-derived neutrophil-activating protein 78 , alpha-1 antitrypsin and latency associated peptide of transforming growth factor beta 1 . For modeling of multiple biomarkers, stepwise regression, with a combination of backwards and forwards selection and a $\mathrm{p}$-value threshold $<0.15$ for entry and exit from the model, was used to arrive at the final model. A p-value of $<0.05$ was taken as statistically significant for association with the outcome emphysema variables.

To perform the meta-analysis, a single variable model was fit for each of the significant biomarkers that were also identified in the TESRA study. Equivalent covariates were included for the two studies and an ordered logistic and linear regression was fit respectively for the \%LAA $\leq-910 \mathrm{HU}$ and LP15A outcomes. P-values from both studies were combined by calculating the average Z-score of the inverse normal quantiles of the two p-values to determine a combined p-value that accounted for consistent effects of the biomarker levels on emphysema severity in the two studies [23]. A Bonferroni adjustment was applied based on all tested markers.

Receiver operating characteristic (ROC) curves were generated for covariates alone and covariates with biomarkers with the presence of emphysema compared to no emphysema as the outcome. Nominal logistic regression was performed, with emphysema considered present if \%LAA $\leq-950 \mathrm{HU}$ was $\geq 5 \%$ compared to no emphysema (\%LAA $\leq-950 \mathrm{HU}<5 \%$ ). Similarly, ROC curves were generated including different severities of airflow limitation based on $\mathrm{FEV}_{1}$ percent predicted. Statistical analyses were performed using JMP 9.0 (SAS Institute, Cary, NC) and R (version 3.0.2) statistical software packages [24].

\section{Results}

\section{Study population}

Demographics, physiology, quantitative HRCT measurements and patient-reported outcomes for COPDGene and TESRA cohorts are listed in Table 1. In the COPDGene biomarker study, there were 588 individuals with complete data available. Subjects with COPD were significantly older, had lower BMI, higher pack-year history of smoking and worse SGRQ scores compared to those without COPD ( $\mathrm{p}<0.01$, all comparisons). The distribution of gender and current smokers was similar between non-COPD and COPD groups. The following variables were associated with emphysema (LAA $\leq-950 \mathrm{HU})$ : lower $\mathrm{FEV}_{1}(\mathrm{p}<0.001)$, lower body mass index $(\mathrm{p}<0.001)$, male gender $(p=0.002)$, older age at enrollment $(p=0.038)$ and current non-smoking status $(\mathrm{p}<0.001)$; these variables 
Table 1 Demographics of individuals in COPDGene and TESRA studies*

\begin{tabular}{|c|c|c|c|c|}
\hline & \multicolumn{3}{|c|}{ COPDGene $(n=588)$} & \multirow{2}{*}{$\begin{array}{l}\text { TESRA } \\
\text { COPD } \\
(n=388)\end{array}$} \\
\hline & $\begin{array}{l}\text { No COPD } \\
n=247\end{array}$ & $\begin{array}{l}\text { COPD } \\
n=341\end{array}$ & p-value & \\
\hline \multicolumn{5}{|l|}{ Demographics } \\
\hline Age (years) & $61 \pm 3$ & $65 \pm 0.5$ & $p<0.01$ & $66.6 \pm 0.4$ \\
\hline Gender (male/female) & $124 / 123$ & $178 / 163$ & $p=0.63$ & $267 / 121$ \\
\hline Current smokers (\%) & 27 & 23 & $p=0.23$ & 0 \\
\hline Smoking history (pack-years) & $38 \pm 1$ & $54 \pm 2$ & $p<0.001$ & $48 \pm 1$ \\
\hline Body mass index $\left(\mathrm{kg} / \mathrm{m}^{2}\right)$ & $28.9 \pm 2.3$ & $27.8 \pm 0.3$ & $p=0.009$ & $26 \pm 0.2$ \\
\hline \multicolumn{5}{|l|}{ Physiology } \\
\hline $\mathrm{FEV}_{1}$ post bronchodilator (\% predicted) & $98 \pm 3.6$ & $47 \pm 1$ & $p<0.001$ & $50 \pm 0.5$ \\
\hline FVC post bronchodilator (\% predicted) & $96 \pm 3.6$ & $79 \pm 1$ & $p<0.001$ & $93 \pm 0.9$ \\
\hline \multicolumn{5}{|l|}{ HRCT measurements } \\
\hline Average $\% \mathrm{LAA} \leq-950 \mathrm{HU}$ & $2.3 \pm 1.6$ & $15 \pm 0.7$ & $p<0.001$ & N/A \\
\hline \% Emphysema <5\% & 85 & 31 & & N/A \\
\hline$\%$ Emphysema 5- <10\% & 13 & 15 & & N/A \\
\hline \% Emphysema 10-<20\% & 2 & 25 & & N/A \\
\hline$\%$ Emphysema $\geq 20 \%$ & 0 & 29 & & N/A \\
\hline Average \% LAA $\leq-910 \mathrm{HU}$ & $22.6 \pm 3.7$ & $39 \pm 0.7$ & $p<0.001$ & $40.7 \pm 0.8$ \\
\hline \% Emphysema <35\% & 79 & 35 & & \\
\hline \% Emphysema 35- <45\% & 15 & 19 & & \\
\hline$\%$ Emphysema $45-<55 \%$ & 5 & 19 & & \\
\hline$\%$ Emphysema $\geq 55 \%$ & 1 & 27 & & \\
\hline Average LP15A & $-916 \pm 4.3$ & $-944 \pm 1.3$ & $p<0.001$ & $-945 \pm 1.3$ \\
\hline \multicolumn{5}{|l|}{ Patient-reported outcomes } \\
\hline MRC dyspnea score & $0.5 \pm 0.1$ & $2.2 \pm 0.1$ & $p<0.001$ & $2.0 \pm 0.03$ \\
\hline SGRQ & $12 \pm 3.9$ & $39 \pm 1.1$ & $p<0.001$ & $46 \pm 0.8$ \\
\hline
\end{tabular}

*Presented are the means \pm standard errors for COPDGene cohort and TESRA cohort. $p$ values represent difference between no COPD and COPD groups for COPDGene. $\mathrm{FEV}_{1}=$ Forced expiratory volume at one second; $\mathrm{FVC}=$ forced vital capacity; $\mathrm{LAA}=$ low area attenuation; N/A = data not available; $\mathrm{LP} 15 \mathrm{~A}=\mathrm{mean}$ lung attenuation value at the $15^{\text {th }}$ percentile on lung attenuation curve. MRC = Medical Research Council; SGRQ = St. George's Respiratory Questionnaire.

were used as covariates for multiple regression (Additional file 1: Table S2).

\section{Biomarkers associated with emphysema}

A full list of biomarkers analyzed in the COPDGene cohort is available (Additional file 1: Table S3). After adjusting for covariates, multiple regression analyses demonstrated a total of 24 biomarkers associated with radiologic emphysema including 15 biomarkers independently associated with \%LAA $\leq-950 \mathrm{HU}\left(\mathrm{R}^{2}=0.4\right), 9$ biomarkers associated with \%LAA $\leq-910 \mathrm{HU}\left(\mathrm{R}^{2}=0.36\right)$ and 16 associated with LP15A $\left(R^{2}=0.64\right.$, Table 2). There were 6 biomarkers that were associated with all 3 radiologic emphysema outcome variables. Advanced glycosylation end-product receptor (RAGE) was negatively associated with more severe emphysema (Figure 1A). In addition, intercellular adhesion molecule 1 (ICAM1, Figure 1B), macrophage inhibitory protein $3 a(C C L 20)$ and cadherin 1 (CDH1, Figure $1 \mathrm{C})$ were negatively associated with emphysema severity. Cadherin 13
(CDH13, Figure 1D) and thyroxin-binding globulin (SERPINA7) were positively correlated with emphysema severity $(\mathrm{p}<0.001$ for all comparisons). There were 3 biomarkers surfactant associated protein D (SFPD), FAS ligand receptor (FAS), and malondialdehyde-modified low-density lipoprotein (MDA LDL) associated with both \%LAA $\leq-910 \mathrm{HU}$ and LP 15 emphysema outcomes (Table 2).

\section{Validation of emphysema biomarkers}

Using similar statistical methods (modeling, covariates, etc.), we attempted to validate the statistically significant biomarkers using an independent cohort from the TESRA study. Although \%LAA $\leq-910 \mathrm{HU}$ and LP15A HRCT data were available in the TESRA cohort, \% LAA $\leq-950 \mathrm{HU}$ measurements were not. Therefore, of the total 16 biomarkers statistically associated with the emphysema outcomes $\leq-910$ and LP15A in the COPDGene cohort, 9 biomarkers were available for validation 
Table 2 Biomarkers and covariates associated with radiologic emphysema in the COPDGene cohort (using multiple regression)*

\begin{tabular}{|c|c|c|c|c|c|c|}
\hline \multirow[b]{2}{*}{ Covariate } & \multicolumn{2}{|l|}{$\%$ LAA $\leq-950 \mathrm{HU}$} & \multicolumn{2}{|l|}{$\%$ LAA $\leq-910 \mathrm{HU}$} & \multicolumn{2}{|l|}{ LP15A } \\
\hline & Beta coefficient & p-value & Beta coefficient & p-value & Beta coefficient & p-value \\
\hline$\overline{\mathrm{FEV}} \mathrm{V}_{1}(\%$ predicted $)$ & -0.07 & $2.9 \times 10^{-40}$ & -0.05 & $6.4 \times 10^{-29}$ & 0.42 & $2.1 \times 10^{-47}$ \\
\hline Body mass index & -0.15 & $3.2 \times 10^{-10}$ & -0.26 & $8.2 \times 10^{-22}$ & 1.37 & $3.4 \times 10^{-21}$ \\
\hline Current active smoking & -1.16 & $9.1 \times 10^{-5}$ & -0.76 & $1.3 \times 10^{-7}$ & 4.56 & $7.5 \times 10^{-7}$ \\
\hline Male gender & 0.35 & 0.002 & 0.71 & $7.3 \times 10^{-9}$ & -9.57 & 0.0001 \\
\hline Age at enrollment & 0.04 & 0.039 & 0.04 & 0.006 & -0.20 & 0.039 \\
\hline \multicolumn{7}{|l|}{ Biomarker } \\
\hline RAGE & -0.69 & $2.6 \times 10^{-8}$ & -1.10 & 0.005 & 10 & 0.0002 \\
\hline CCL20 (presence) & -0.45 & 0.0006 & -0.35 & 0.004 & 2.12 & 0.009 \\
\hline ICAM1 & -0.42 & 0.001 & -2.40 & 0.007 & 28.39 & $3.4 \times 10^{-6}$ \\
\hline SERPINA7" & 0.28 & 0.013 & 2.11 & 0.042 & -13.69 & 0.038 \\
\hline $\mathrm{CDH} 13^{\pi}$ & 0.29 & 0.025 & 2.62 & 0.005 & -16.91 & 0.008 \\
\hline $\mathrm{CDH} 1^{\pi}$ & -0.25 & 0.039 & -2.04 & 0.006 & 13.09 & 0.006 \\
\hline TGFB1 LAP & -0.54 & 0.0002 & & & & \\
\hline CCL13 & 0.35 & 0.013 & & & & \\
\hline TNFRSF11B & 0.34 & 0.016 & & & & \\
\hline CCL8 & -0.27 & 0.023 & & & & \\
\hline $\lg A$ & -0.25 & 0.03 & & & 6.09 & 0.025 \\
\hline SORT1 & -0.26 & 0.038 & & & & \\
\hline IL2RA & 0.27 & 0.044 & & & & \\
\hline CCL2 & 0.25 & 0.045 & & & & \\
\hline IL12B (presence) & 0.22 & 0.049 & & & & \\
\hline MDA LDL (absence) ${ }^{\pi}$ & & & 0.33 & 0.016 & -2.07 & 0.025 \\
\hline FAS & & & 1.16 & 0.016 & -8.53 & 0.014 \\
\hline SFTPD & & & -1.16 & 0.025 & 8.34 & 0.016 \\
\hline$A X L$ & & & & & 17.05 & 0.002 \\
\hline CXCL10 & & & & & -11.80 & 0.002 \\
\hline ADIPOQ & & & & & -7.26 & 0.015 \\
\hline$M B^{\pi}$ & & & & & -7.97 & 0.016 \\
\hline SOD1 & & & & & 11.08 & 0.009 \\
\hline NRCAM & & & & & -9.26 & 0.017 \\
\hline
\end{tabular}

*Presented are beta coefficients and $\mathrm{p}$ values for multiple regression models of biomarkers and covariates associated with emphysema outcomes. \%LAA = Percent low attenuation areas; $L P 15 A=$ mean lung attenuation at $15^{\text {th }}$ percentile on lung attenuation curve; $H_{U}=H_{\text {Hounsfield }}$ units; FEV ${ }_{1}=$ Forced expiratory volume in $1^{\text {st }}$ second; RAGE = Receptor for advanced glycosylation end products; CCL20 = Macrophage Inflammatory Protein-3 alpha; ICAM1 = Intercellular Adhesion Molecule 1; SERPINA7 = Thyroxin-binding globulin; CDH 13 = Cadherin-13; CDH1 = Cadherin-1; TGFB1 LAP = Latency-Associated Peptide of Transforming Growth Factor beta 1; CCL13 = Monocyte Chemotactic Protein 4; TNFRSF11B = Osteoprotegerin; CCL8 = Monocyte Chemotactic Protein 2; IgA = Immunoglobulin A; SORT1 = Sortilin; IL2RA = Interleukin-2 receptor alpha; CCL2 = Monocyte Chemotactic Protein 1; IL-12B = Interleukin-12 Subunit p40; MDA LDL = Malondialdehyde-Modified Low-Density Lipoprotein; FAS = FASLG Receptor; SFTPD = Surfactant protein D; AXL = AXL Receptor Tyrosine Kinase; CXCL10 = Interferon gamma Induced Protein 10; $A D I P O Q=A d i p o n e c t i n ; ~ M B=$ Myoglobin; SOD1 = Superoxide dismutase 1; NRCAM = Neuronal Cell Adhesion Molecule.

\#Higher LP15A values indicate less severe emphysema, so positive coefficients are associated with less severe emphysema and negative coefficients are associated with more severe emphysema unlike higher \%LAA which is associated with more severe emphysema.

"Biomarkers not available for replication in TESRA.

in TESRA cohort. After meta-analysis and adjustment for multiple testing, biomarkers RAGE $\left(\mathrm{p}=1.2 \times 10^{-9}\right)$ and ICAM1 $\left(\mathrm{p}=1.5 \times 10^{-7}\right)$ were associated with \% LAA $<-910 \mathrm{HU}$ (Table 3). Similarly, with regard to the LP15A emphysema outcome variable, meta-analysis with the TESRA cohort validated the association of
RAGE $\left(p=2.5 \times 10^{-10}\right)$, ICAM1 $\left(p=6.0 \times 10^{-11}\right)$, and AXL $\left(\mathrm{p}=3.8 \times 10^{-3}\right)$ with radiologic emphysema independent of covariates (Table 3). CCL20 was significantly negatively associated with emphysema in both the TESRA and COPDGene cohorts; however, metaanalysis was not possible due to CCL20 being binary in 

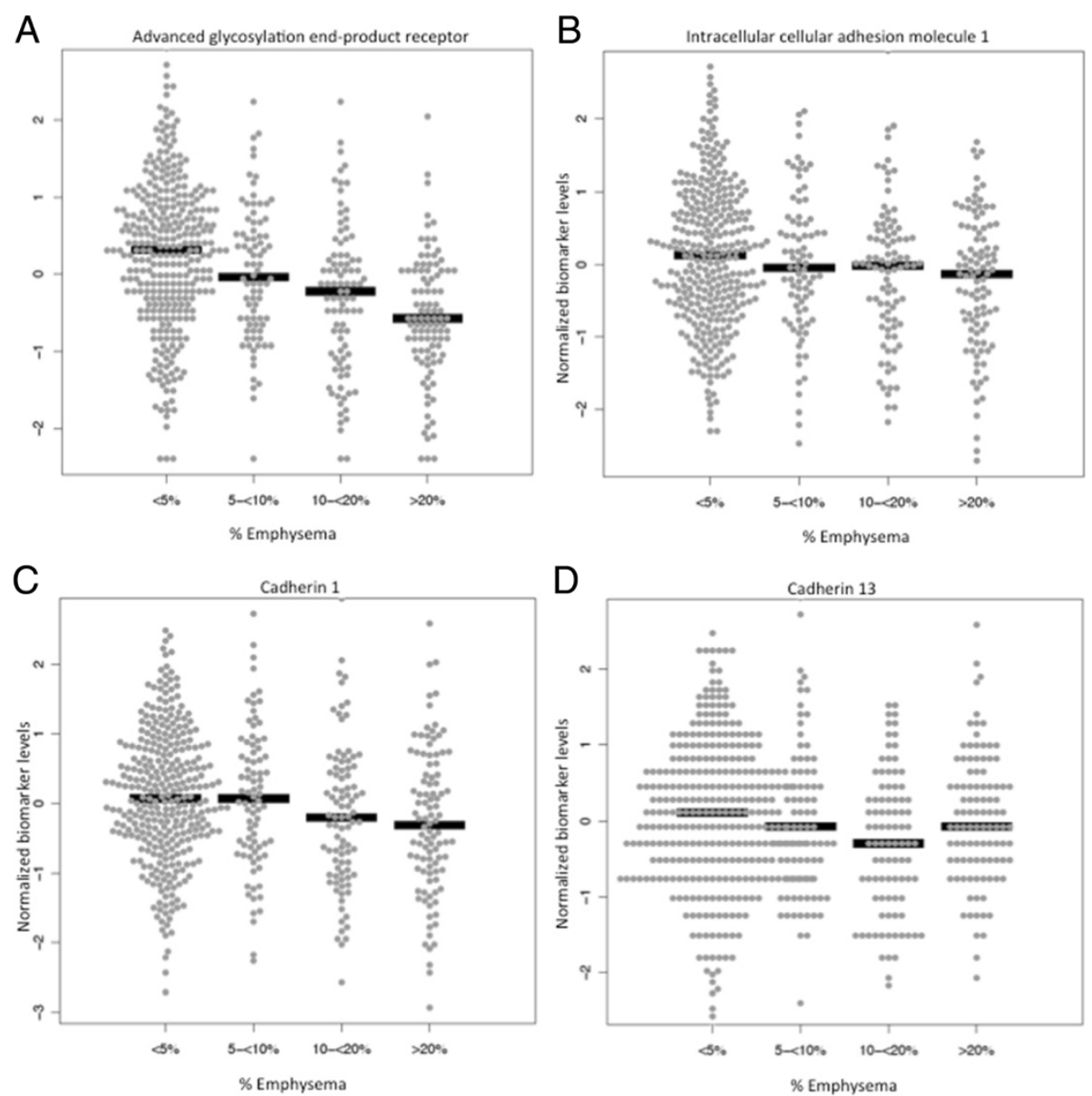

Figure 1 Biomarkers associated with CT-assessed emphysema in the COPDGene cohort. (A) Advanced glycosylation end-product receptor (RAGE); (B) Intracellular adhesion molecule 1 (ICAM1); (C) Cadherin 1 (CDH1); (D) Cadherin 13 (CDH13). *Presented are normal quantile transformed biomarker levels on the ordinate and percent emphysema (\% low attenuation $\leq-950 \mathrm{HU}$ ) on $C T$ scan on abscissa ( $p<0.001$ for all comparisons).

Table 3 Meta-analysis of biomarkers associated with emphysema in COPDGene and TESRA cohorts*

\begin{tabular}{|c|c|c|c|c|c|}
\hline \multirow[b]{2}{*}{ Variable } & \multicolumn{2}{|l|}{ COPDGene } & \multicolumn{2}{|l|}{ TESRA } & \multirow{2}{*}{$\begin{array}{l}\text { Adjusted } \\
\text { meta-analysi } \\
\text { p-value }\end{array}$} \\
\hline & Beta coefficient & p-value ${ }^{\circ}$ & Beta coefficient & p-value ${ }^{\circ}$ & \\
\hline \multicolumn{6}{|c|}{ Percent LAA $\leq-910 \mathrm{HU}$} \\
\hline RAGE & -1.4 & $2.6 \times 10^{-5}$ & -0.52 & $9.2 \times 10^{-7}$ & $1.2 \times 10^{-9}$ \\
\hline ICAM1 & -3.2 & $9.2 \times 10^{-6}$ & -0.37 & $3.4 \times 10^{-4}$ & $1.5 \times 10^{-7}$ \\
\hline $\mathrm{CCL} 20^{\#}$ & -0.87 & $1.3 \times 10^{-4}$ & -0.29 & $2.2 \times 10^{-3}$ & $\mathrm{~N} / \mathrm{A}$ \\
\hline \multicolumn{6}{|c|}{ Mean lung attenuation at $15^{\text {th }}$ percentile } \\
\hline RAGE & 10.78 & $1.3 \times 10^{-5}$ & 7.08 & $3.0 \times 10^{-8}$ & $2.5 \times 10^{-10}$ \\
\hline ICAM1 & 32.3 & $1.1 \times 10^{-9}$ & 5.14 & $4.5 \times 10^{-5}$ & $6.0 \times 10^{-11}$ \\
\hline$A X L$ & 18.8 & $1.8 \times 10^{-4}$ & 2.53 & 0.038 & $3.8 \times 10^{-3}$ \\
\hline $\mathrm{CCL} 20^{\#}$ & 6.44 & $8.2 \times 10^{-5}$ & 4.45 & $1.3 \times 10^{-4}$ & N/A \\
\hline
\end{tabular}

*Presented is the regression analysis for each biomarker with an adjusted meta-analysis $\mathrm{p}$ value. LAA = low attenuation area; RAGE $=$ Receptor for advanced glycosylation end products; ICAM1 = Intercellular Adhesion Molecule 1; CCL20 = Macrophage Inflammatory Protein-3 alpha; AXL = AXL Receptor Tyrosine Kinase; ${ }^{\circ} \mathrm{p}$ values for COPDGene and TESRA are two-sided $p$ values.

${ }^{\#}$ CCL20 was a binary variable in COPDGene, therefore it is the presence CCL20 that is negatively associated with emphysema in COPDGene cohort, while CCL20 was a continuous variable in TESRA also associated negatively associated with more severe emphysema. Meta-analysis was not possible given difference in variables (N/A). 
COPDGene and continuous in TESRA. Biomarkers significant in the COPDGene study such as CDH1, CDH13, SERPINA7, MDA LDL, MB, NRCAM, and ADIPOQ were not measured in the TESRA study and therefore could not be included in the meta-analysis.

ROC curves for covariates age, gender, BMI, current smoking status and $\mathrm{FEV}_{1}$ had an area under the curve (AUC) of 0.88 for the prediction of emphysema. ROC curves demonstrated a slight improvement in the AUC after adding 15 biomarkers to the model, raising the AUC to 0.92 (Additional file 1: Table S4 and Figure S1). However, when only considering those without severe airflow limitation $\left(\mathrm{FEV}_{1} \geq 50 \%, \mathrm{n}=399\right)$, the AUC was 0.78 using covariates alone and the AUC increased to 0.85 when the biomarker panel was added to the model.

\section{Discussion}

COPD is a phenotypically heterogeneous disease, with the presence of emphysema having implications for risk stratification and management $[3-5,18]$. In this study, we successfully identified and replicated a panel of peripheral blood biomarkers that was associated with emphysema independent of age, smoking status, body mass index, airflow limitation, and gender. These biomarkers (AGER, ICAM1 and CCL20) were associated with emphysema regardless of quantification technique (\%LAA $\leq-950$ and $\leq-910 \mathrm{HU}$ and LP15A) and were replicated in an independent COPD cohort (TESRA), thus strengthening their potential utility for defining clinically relevant emphysema.

Our study reports lower RAGE levels in peripheral blood as a biomarker of increased emphysema percentage in the lungs independent of gender, age, airflow limitation, body mass index and current smoking status. RAGE (advanced glycosylation end-product receptor or AGER) is an immunoglobulin family member that is highly expressed in human lung [25]. The RAGE pathway and soluble RAGE (sRAGE), a splice variant or proteolytic cleavage product of RAGE, have been associated with several inflammatory conditions such as diabetes mellitus, vascular disease and arthritis [26,27]. The sRAGE molecule binds damaged ligands preventing these from binding to cell surface receptors and activating cell signaling pathways [28]. RAGE is active in damage-related conditions such as hyperglycemia, hypoxia, inflammation and oxidative stress [29]. While fasting blood glucose measurements were not available, 66 individuals reported a history of diabetes mellitus in the COPDGene biomarker study and there was no association between RAGE levels and self-reported history of diabetes mellitus $(p=0.88)$. Lower levels of sRAGE have been described in individuals with airflow limitation [30,31]. Other studies have found lower sRAGE levels associated with CT-assessed emphysema severity and cor pulmonale [32] and with CT-assessed emphysema and lower diffusing capacity of carbon monoxide using the TESRA data described in this study in combination with the ECLIPSE investigators [13]. Some studies suggest that sRAGE is increased in the lungs of patients with COPD and high levels of sRAGE may be associated with progression of emphysema [33]. Interestingly, animal studies suggest RAGE/sRAGE plays a role in alveolar development and overexpression in mouse lung leads to the development of emphysema [34]. This suggests that sRAGE, by acting as a decoy molecule, may have a different role in the developing lung and the adult lung or low sRAGE levels in COPD may result in increased inflammatory signaling in the lung.

In the present study, we found decreased ICAM1 levels correlate with increased severity of emphysema on CT scan, independent of smoking status, $\mathrm{FEV}_{1}$ and other covariates. ICAM1 is expressed on vascular endothelial and immune cells and mediates cell transmigration and adhesion [35]. ICAM1 plays a role in the recruitment of inflammatory cells to the lung. There is currently quite limited information about the association of ICAM1 to COPD and emphysema. Higher serum levels of soluble ICAM1 have been demonstrated in COPD, where it correlated with the severity of airflow limitation, arterial hypoxemia and hypercarbia [36,37]. Other studies relate ICAM1 levels to active smoking [38] and preliminary analysis from The MESA Lung Study demonstrated that ICAM1 predicted $0.15 \%$ /year increase in CT-assessed emphysema, suggesting a role for this molecule as a biomarker of emphysema and that it may play a role in emphysema pathogenesis [39].

CCL20 or macrophage inhibitory protein $3 \mathrm{a}$, a chemokine receptor ligand, is involved in the recruitment of inflammatory cells through chemokine receptor 6 (CCR6), its only known receptor [40]. In both the COPDGene study and the TESRA study, CCL20 levels were inversely and significantly associated with emphysema although methodological considerations prevented a meta-analysis. Lower CCL20 levels have been described in bronchoalveolar lavage fluid of smokers [41]. The CCR6/CCL20 complex is one of the most potent regulators of dendritic cell migration to the lung and CCR6 knockout mice may be partially protected against cigarette smoke-induced emphysema due to reduced recruitment of inflammatory cells to the lung [42]. These data suggest that increased activity of the CCL20/CCR6 pathway may increase the susceptibility to emphysema.

CDH1 was negatively correlated with radiologic emphysema across all emphysema outcome measurements. $\mathrm{CDH} 1$ or $\mathrm{E}$ cadherin is an epithelial cell adhesion molecule that regulates cell differentiation and morphogenesis, and is associated with lung fibrosis and cancer [43]. CDH1 may be a marker of epithelial cell injury and epithelial to mesenchymal transition that is believed to play a role in small airway remodeling in COPD [44]. Genetic polymorphisms in 
CDH1 have been associated with development of COPD and decline in lung function [45]. $\mathrm{CDH} 13$ or $\mathrm{H}$ cadherin is another adhesion molecule that may influence surfactant protein D levels and serum adiponectin levels, both implicated in the pathogenesis of COPD; however, CDH13 itself has not been associated with quantitative emphysema to date $[46,47]$. We found higher levels of CDH13 to be associated with CT-assessed emphysema in the COPDGene cohort, but these were not available for validation in the TESRA cohort. Higher SERPINA7 levels were also associated with more radiologic emphysema. SERPINA7 does not have protease inhibitor capabilities and is also known as thyroid binding globulin. This study represents a new association for SERPINA7 with COPD.

With regard to the ability of biomarkers to predict the presence of any emphysema compared to no emphysema, ROC curves demonstrated a small contribution of plasma biomarkers separate to the covariates alone. This is likely because when individuals with more severe levels of emphysema are included, covariates alone, especially $\mathrm{FEV}_{1}$, are highly predictive of emphysema in their own right. However, the biomarkers are more useful for predicting the presence of emphysema in those that do not already have severe airflow limitation, because the covariates alone were not as good at predicting emphysema in this group and biomarkers combined with covariates increased the area under the curve. This may be useful clinically since determining the presence of underlying emphysema at this early stage in those that do not yet have severe airflow limitation may have outcome benefits for the individuals [3-6].

This COPDGene biomarker study is one of the largest emphysema biomarker studies to date on carefully phenotyped individuals with COPD. The TESRA cohort provides validation of a number of the findings. The study confirms a previously identified association between radiologic emphysema and sRAGE, builds on data suggesting a role for ICAM1 as a biomarker, in addition to discovering previously not identified biomarkers associated with emphysema such as CCL20, cadherin 1, cadherin 13 and SERPINA7. The study also highlights the potential usefulness of a panel of biomarkers to predict the presence of emphysema compared to using clinical data alone, especially in those who do not yet have severe abnormalities in lung function. However there are limitations; the TESRA cohort was different from the COPDGene cohort in that its population was comprised of ex-smokers with at least mild COPD and did not include control subjects and only 2 of the 3 quantitative emphysema measurements were made ( -910 HU and LP15A). Since emphysema can occur in smokers without COPD and emphysema measurements are highly co-linear, these limitations may be of minor importance. Other limitations include the fact that the majority of subjects in both cohorts were non-Hispanic white, thus, the generalizability of these findings to other populations remains unknown and emphysema measurements from both COPDGene and TESRA were cross sectional; therefore, the significance of these biomarkers for emphysema progression remains unknown. A final limitation of this study, an in many biomarker studies, is the magnitude of association between the change in biomarker levels and the change in emphysema severity. While the biomarker associations are highly statistically significant, and validation suggests the associations are real, further studies are needed to evaluate the role of these biomarkers in disease pathogenesis and as markers of disease presence and progression $[48,49]$.

\section{Conclusion}

Our findings, particularly when combined with other studies of individual biomarkers, suggest that a panel of blood biomarkers including sRAGE, ICAM1 and CCL20 may serve as a useful surrogate measure of emphysema and may shed light on disease pathogenesis, providing targets for new treatments. Other biomarkers such as CHD1, CDH13 and SERPINA7 may also have a role in evaluating emphysema (especially milder emphysema), although require confirmation in other cohorts. Overall, these peripheral blood biomarkers could ultimately be used to diagnose emphysema at subclinical stages thereby reducing the need for $\mathrm{CT}$, and perhaps may provide insights into disease prediction and progression.

\section{Additional file}

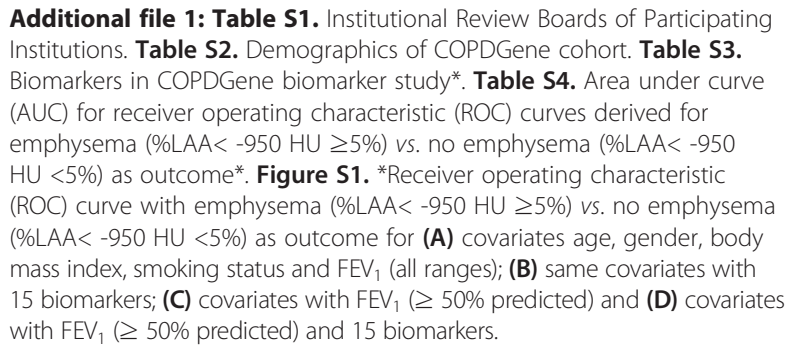

\section{Abbreviations}

ADIPOQ: Adiponectin; AGER/RAGE: Advanced glycosylation end products receptor; AXL: AXL Receptor Tyrosine Kinase; CCL13: Monocyte chemotactic protein 4; CCL2: Monocyte chemotactic protein 1; CCL20: Macrophage inflammatory protein-3 alpha; CCL8: Monocyte chemotactic protein 2; CDH 13: Cadherin-13; CDH1: Cadherin-1; COPD: Chronic obstructive pulmonary disease; CXCL10: Interferon gamma induced protein 10; FAS: FASLG receptor; FEV1: Forced expiratory volume in first second; FVC: Forced vital capacity; HRCT: High resolution computed tomography; HU: Hounsfield units; ICAM1: Intercellular adhesion molecule 1; IgA: Immunoglobulin A; IL-12B: Interleukin-12 Subunit p40; IL2RA: Interleukin-2 receptor alpha; LAA: Low attenuation area; LLOQ: Lower limit of quantitation; LP15A: Mean lung attenuation at the $15^{\text {th }}$ percentile on lung attenuation curve;

MB: Myoglobin; MDA LDL: Malondialdehyde-modified low-density lipoprotein; NRCAM: Neuronal cell adhesion molecule; SERPINA7: Thyroxin-binding globulin; SFTPD: Surfactant protein D; SOD1: Superoxide dismutase 1; SORT1: Sortilin; TGFB1 LAP: Latency-associated peptide of transforming growth factor beta 1; TNFRSF11B: Osteoprotegerin. 


\section{Competing interests}

Dr. Carolan: The author has received lecture fees from Novartis. Dr. Hersh: The author is a consultant for CSL Behring and receives lecture fees from Novartis. Dr. Rennard: Entities with which SIR currently has relationships are as follows: GlaxoSmithKline, Boehringer Ingelheim, Forest, AstraZeneca, Chiesi, CME Incite, Takeda, Regeneron, Pearl, CIPLA, CSA, American Board of Internal Medicine, Merck, Medimmune, Synapse, Nycomed, Dalichi Sankyo, Novartis, Johnson and Johnson, Quadrant, Gerson Lehman, Able Associates, CSL Behring, CTS Carmel, Decision Resources, FirstWord, Gilead, Guidepoint Global, Pulmatrix, Saatchi and Saatchi, Schlesinger Associates, Cory Paeth, Frankel Group, Medical Knowledge, Pro Ed Communication, LEX Consulting. Dr. Belloni: The author is an employee of Genentech and receives stock or stock options from Genentech/Roche. Dr. Comellas: The author is a consultant for VIDA diagnostics. The other authors declare that they have no competing interests.

\section{Authors' contributions}

BJC: Contributed to the data acquisition, analysis, and interpretation, manuscript drafting and critical review for intellectual content and final approval of the manuscript. BJC had full access to all of the data in the study and takes responsibility for the integrity of the data and the accuracy of the data analysis. GH: Contributed to the data analysis and interpretation, critical review for important intellectual content and final approval of the manuscript. JM: Contributed to the TESRA data analysis and interpretation. CPH: Contributed to TESRA data acquisition, analysis and critical review for the important intellectual content, and final approval of the manuscript. WKO: Critical review for the important intellectual content and final approval of the manuscript. SR: Critical review for the important intellectual content and final approval of the manuscript. SGP: Contributed to TESRA data acquisition, analysis and critical review for the important intellectual content, and final approval of the manuscript. PB: Contributed to TESRA data acquisition, analysis and critical review for the important intellectual content, and final approval of the manuscript. DAC: Contributed to TESRA data acquisition, analysis and critical review for the important intellectual content, and final approval of the manuscript. APC: Contributed to data acquisition, analysis and critical review for the important intellectual content and final approval of the manuscript. MH: Critical review for the important intellectual content and final approval of the manuscript. RLZ: Critical review for important intellectual content and final approval of the manuscript KK: Contributed to the data analysis and interpretation and drafting, critical review for important intellectual content, and final approval of the manuscript. RPB: Contributed to the study conception and design; data analysis and interpretation; manuscript drafting, critical review for the important intellectual content, and final approval of the manuscript. All authors read and approved the final manuscript.

\section{Acknowledgements}

The authors would like to thank Sarah Hawthorne for editorial assistance.

\section{Funding support}

This study was supported by National Heart, Lung and Blood Institute (NHLBI RO1HL 095432, U01 HL089856, U01 HL089897, P20 HL113445); UL1 RR025780 from NCRR/HIH and HHSN26820090020CP30 from NHLBI.

\section{Author details}

${ }^{1}$ Department of Medicine, National Jewish Health, 1400 Jackson St, Denver, CO 80206, USA. ${ }^{2}$ Department of Medicine, University of Colorado School of Medicine, Aurora, CO, USA. ${ }^{3}$ Department of Biostatistics and Informatics, Colorado School of Public Health, University of Colorado Denver, Aurora, CO, USA. ${ }^{4}$ Channing Division of Network Medicine, Brigham and Women's Hospital and Harvard Medical School, Boston, MA, USA. ${ }^{5}$ Cystic Fibrosis/ Pulmonary Research and Treatment Center, Department of Medicine, University of North Carolina at Chapel Hill, Chapel Hill, NC, USA. 'Department of Internal Medicine, Pulmonary, Critical Care and Allergy Division, University of Nebraska Medical Center, Omaha, NE, USA. ${ }^{7}$ Hoffman La Roche, Nutley, USA. ${ }^{8}$ Genentech, Member of the Roche Group, South San Francisco, CA, USA. ${ }^{9}$ Department of Internal Medicine, University of lowa, lowa City, IA, USA. ${ }^{10}$ Department of Internal Medicine, Division of Pulmonary and Critical Care, University of Michigan Health System, Ann Arbor, MI, USA. ${ }^{11}$ Current address: Eli Lilly and Company, Lilly Corporate Center, Indianapolis, IN, USA. ${ }^{2}$ Current address: Boston Scientific, San Jose, CA, USA.
Received: 29 May 2014 Accepted: 3 October 2014

Published online: 12 October 2014

\section{References}

1. Vestbo J, Hurd SS, Agusti AG, Jones PW, Vogelmeier C, Anzueto A, Barnes PJ, Fabbri LM, Martinez FJ, Nishimura M, Stockley RA, Sin DD, Rodriguez-Roisin R: Global strategy for the diagnosis, management, and prevention of chronic obstructive pulmonary disease: GOLD executive summary. Am J Respir Crit Care Med 2013, 187(4):347-365.

2. Fletcher CM, Gilson JG, Hugh-Jones P, Scadding JG: Terminology, definitions, and classification of chronic pulmonary emphysema and related conditions. Thorax 1959, 14:286-299.

3. Mohamed Hoesein FA, Zanen P, Boezen HM, Groen HJ, van Ginneken B, de Jong PA, Postma DS, Lammers JW: Lung function decline in male heavy smokers relates to baseline airflow obstruction severity. Chest 2012, 142(6):1530-1538.

4. Li Y, Swensen SJ, Karabekmez LG, Marks RS, Stoddard SM, Jiang R, Worra JB, Zhang F, Midthun DE, de Andrade M, Song Y, Yang P: Effect of emphysema on lung cancer risk in smokers: a computed tomographybased assessment. Cancer Prev Res (Phila) 2011, 4(1):43-50.

5. de Torres JP, Bastarrika G, Wisnivesky JP, Alcaide AB, Campo A, Seijo LM, Pueyo JC, Villanueva A, Lozano MD, Montes U, Montuenga L, Zulueta JJ: Assessing the relationship between lung cancer risk and emphysema detected on low-dose CT of the chest. Chest 2007, 132(6):1932-1938.

6. Haruna A, Muro S, Nakano Y, Ohara T, Hoshino Y, Ogawa E, Hirai T, Niimi A, Nishimura K, Chin K, Mishima M: CT scan findings of emphysema predict mortality in COPD. Chest 2010, 138(3):635-640.

7. Bastarrika G, Wisnivesky JP, Pueyo JC, Diaz L, Arraiza M, Villanueva A, Alcaide AB, Campo A, Seijo L, de Torres JP, Zulueta JJ: Low-dose volumetric computed tomography for quantification of emphysema in asymptomatic smokers participating in an early lung cancer detection trial. J Thorac Imaging 2009, 24(3):206-211.

8. Kirby M, Coxson HO: Computed tomography biomarkers of pulmonary emphysema. COPD 2013, 10(4):547-550.

9. Schroeder JD, McKenzie AS, Zach JA, Wilson CG, Curran-Everett D, Stinson DS, Newell JD Jr, Lynch DA: Relationships between airflow obstruction and quantitative CT measurements of emphysema, air trapping, and airways in subjects with and without chronic obstructive pulmonary disease. AJR Am J Roentgenol 2013, 201(3):W460-W470.

10. Mendoza CS, Washko GR, Ross JC, Diaz AA, Lynch DA, Crapo JD, Silverman EK, Acha B, Serrano C, Estepar RS: Emphysema Quantification in a Multi-Scanner Hrct Cohort Using Local Intensity Distributions. Proc IEEE Int Symp Biomed Imaging 2013: 474-477.

11. Parr DG, Dirksen A, Piitulainen E, Deng C, Wencker M, Stockley RA: Exploring the optimum approach to the use of CT densitometry in a randomised placebo-controlled study of augmentation therapy in alpha 1-antitrypsin deficiency. Respir Res 2009, 10:75.

12. Stoller JK, Aboussouan LS: A review of alpha1-antitrypsin deficiency. Am J Respir Crit Care Med 2012, 185(3):246-259.

13. Cheng DT, Kim DK, Cockayne DA, Belousov A, Bitter H, Cho MH, Duvoix A, Edwards LD, Lomas DA, Miller BE, Reynaert N, Tal-Singer R, Wouters EF, Agusti A, Fabbri LM, Rames A, Visvanathan S, Rennard SI, Jones P, Parmar H, MacNee W, Wolff G, Silverman EK, Mayer RJ, Pillai SG: Systemic soluble receptor for advanced glycation endproducts is a biomarker of emphysema and associated with AGER genetic variants in patients with chronic obstructive pulmonary disease. Am J Respir Crit Care Med 2013, 188(8):948-957.

14. Carolan BJ, Kim YI, Williams AA, Kechris K, Lutz S, Reisdorph N, Bowler RP: The association of adiponectin with computed tomography phenotypes in chronic obstructive pulmonary disease. Am J Respir Crit Care Med 2013, 188(5):561-566.

15. Miller M, Ramsdell J, Friedman PJ, Cho JY, Renvall M, Broide DH: Computed tomographic scan-diagnosed chronic obstructive pulmonary diseaseemphysema: eotaxin-1 is associated with bronchodilator response and extent of emphysema. J Allergy Clin Immunol 2007, 120(5):1118-1125.

16. Thomsen M, Dahl M, Lange P, Vestbo J, Nordestgaard BG: Inflammatory biomarkers and comorbidities in chronic obstructive pulmonary disease. Am J Respir Crit Care Med 2012, 186(10):982-988.

17. Gaki E, Kontogianni K, Papaioannou Al, Bakakos P, Gourgoulianis KI, Kostikas K, Alchanatis M, Papiris S, Loukides S: Associations between BODE index and systemic inflammatory biomarkers in COPD. COPD 2011, 8(6):408-413. 
18. Rosenberg SR, Kalhan R: Biomarkers in chronic obstructive pulmonary disease. Transl Res 2012, 159(4):228-237.

19. Regan EA, Hokanson JE, Murphy JR, Make B, Lynch DA, Beaty TH, Curran-Everett D, Silverman EK, Crapo JD: Genetic epidemiology of copd (copedgene) study design. COPD 2010, 7:32-43.

20. Jones PW: Tesra (treatment of emphysema with selective retinoid agonist) study results. Am J Respir Crit Care Med 2011, 183:A6418.

21. Han MK, Kazerooni EA, Lynch DA, Liu LX, Murray S, Curtis JL, Criner GJ, Kim V, Bowler RP, Hanania NA, Anzueto AR, Make BJ, Hokanson JE, Crapo JD, Silverman EK, Martinez FJ, Washko GR: Chronic obstructive pulmonary disease exacerbations in the COPDGene study: associated radiologic phenotypes. Radiology 2011, 261(1):274-282.

22. O'Neal WK, Anderson W, Basta PV, Carretta EE, Doerschuk CM, Barr RG, Bleecker ER, Christenson SA, Curtis JL, Han MK, Hansel NN, Kanner RE, Kleerup EC, Martinez FJ, Miller BE, Peters SP, Rennard SI, Scholand MB, Tal-Singer R, Woodruff PG, Couper DJ, Davis SM: Comparison of serum, EDTA plasma and P100 plasma for luminex-based biomarker multiplex assays in patients with chronic obstructive pulmonary disease in the SPIROMICS study. J Transl Med 2014, 12:9.

23. Stouffer SA, Suchman EA, DeVinney LC, Star SA, Williams RM Jr: The American Soldier, Vol. 1: Adjustment during Army Life. Princeton: Princeton University Press; 1949.

24. Murdoch DR, O'Brien KL, Scott JA, Karron RA, Bhat N, Driscoll AJ, Knoll MD, Levine OS: Breathing new life into pneumonia diagnostics. J Clin Microbiol 2009, 47(11):3405-3408.

25. Buckley ST, Ehrhardt C: The receptor for advanced glycation end products (RAGE) and the lung. J Biomed Biotechnol 2010, 2010:917108.

26. Pullerits R, Bokarewa M, Dahlberg L, Tarkowski A: Decreased levels of soluble receptor for advanced glycation end products in patients with rheumatoid arthritis indicating deficient inflammatory control. Arthritis Res Ther 2005, 7(4):R817-R824.

27. Falcone C, Bozzini S, Guasti L, D'Angelo A, Capettini AC, Paganini EM, Falcone R, Moia R, Gazzaruso C, Pelissero G: Soluble RAGE plasma levels in patients with coronary artery disease and peripheral artery disease. Scientific World Journal 2013, 2013:584504.

28. Alexiou P, Chatzopoulou M, Pegklidou K, Demopoulos VJ: RAGE: a multi-ligand receptor unveiling novel insights in health and disease. Curr Med Chem 2010, 17(21):2232-2252.

29. Uchida T, Shirasawa M, Ware LB, Kojima K, Hata Y, Makita K, Mednick G, Matthay ZA, Matthay MA: Receptor for advanced glycation end-products is a marker of type I cell injury in acute lung injury. Am I Respir Crit Care Med 2006, 173(9):1008-1015.

30. Smith DJ, Yerkovich ST, Towers MA, Carroll ML, Thomas R, Upham JW: Reduced soluble receptor for advanced glycation end-products in COPD. Eur Respir J 2011, 37(3):516-522.

31. Cockayne DA, Cheng DT, Waschki B, Sridhar S, Ravindran P, Hilton H, Kourteva G, Bitter H, Pillai SG, Visvanathan S, Muller KC, Holz O, Magnussen $\mathrm{H}_{\text {, }}$ Watz H, Fine JS: Systemic biomarkers of neutrophilic inflammation, tissue injury and repair in COPD patients with differing levels of disease severity. PLoS One 2012, 7(6):e38629.

32. Miniati M, Monti S, Basta G, Cocci F, Fornai E, Bottai M: Soluble receptor for advanced glycation end products in COPD: relationship with emphysema and chronic cor pulmonale: a case-control study. Respir Res 2011, 12:37.

33. Wu L, Ma L, Nicholson LF, Black PN: Advanced glycation end products and its receptor (RAGE) are increased in patients with COPD. Respir Med 2011, 105(3):329-336.

34. Stogsdill MP, Stogsdill JA, Bodine BG, Fredrickson AC, Sefcik TL, Wood TT, Kasteler SD, Reynolds PR: Conditional overexpression of receptors for advanced glycation end-products in the adult murine lung causes airspace enlargement and induces inflammation. Am J Respir Cell Mol Biol 2013, 49(1):128-134.

35. Di Stefano A, Maestrelli P, Roggeri A, Turato G, Calabro S, Potena A, Mapp CE, Ciaccia A, Covacev L, Fabbri LM, Saetta M: Upregulation of adhesion molecules in the bronchial mucosa of subjects with chronic obstructive bronchitis. Am J Respir Crit Care Med 1994, 149(3 Pt 1):803-810.

36. El-Deek SE, Makhlouf HA, Saleem TH, Mandour MA, Mohamed NA: Surfactant protein $D$, soluble intercellular adhesion molecule-1 and high-sensitivity C-reactive protein as biomarkers of chronic obstructive pulmonary disease. Med Princ Pract 2013, 22(5):469-474.
37. Huang H, Jiang H, Kong X, Liu T, Tan Z, Chen P, Luo H: Association of intercellular adhesion molecule-1 gene K469E polymorphism with chronic obstructive pulmonary disease. Zhong Nan Da Xue Xue Bao Yi Xue Ban 2012, 37(1):78-83.

38. Lopez-Campos JL, Calero C, Arellano-Orden E, Marquez-Martin E, Cejudo-Ramos P, Ortega Ruiz F, Montes-Worboys A: Increased levels of soluble ICAM-1 in chronic obstructive pulmonary disease and resistant smokers are related to active smoking. Biomark Med 2012, 6(6):805-811.

39. Aaron CP, Schwartz JE, Tracy R, Hoffman EA, Austin JHM, Oelsner EC, Donohue KM, Kalhan R, Jacobs D, Barr RG: Intercellular Adhesion Molecule (icam)1 And Longitudinal Change In Percent Emphysema And Lung Function: The MESA Lung Study. Am J Respir Crit Care Med 2013, 187:A1523.

40. Dieu-Nosjean MC, Massacrier C, Homey B, Vanbervliet B, Pin JJ, Vicari A, Lebecque S, Dezutter-Dambuyant C, Schmitt D, Zlotnik A, Caux C: Macrophage inflammatory protein 3alpha is expressed at inflamed epithelial surfaces and is the most potent chemokine known in attracting Langerhans cell precursors. J Exp Med 2000, 192(5):705-718

41. Meuronen A, Majuri ML, Alenius H, Mantyla T, Wolff H, Piirila P, Laitinen A: Decreased cytokine and chemokine mRNA expression in bronchoalveolar lavage in asymptomatic smoking subjects. Respiration 2008, 75(4):450-458.

42. Bracke KR, D'Hulst Al, Maes T, Moerloose KB, Demedts IK, Lebecque S, Joos GF, Brusselle GG: Cigarette smoke-induced pulmonary inflammation and emphysema are attenuated in CCR6-deficient mice. J Immunol 2006, 177(7):4350-4359.

43. Gall TM, Frampton AE: Gene of the month: E-cadherin (CDH1). J Clin Pathol 2013, 66(11):928-932.

44. Milara J, Peiro T, Serrano A, Cortijo J: Epithelial to mesenchymal transition is increased in patients with COPD and induced by cigarette smoke. Thorax 2013, 68(5):410-420.

45. Tsuduki KNH, Nakajima T, Tsujimura S, Yoshida S, Takahashi E, Nakamura M, Minematsu N, Tateno H, Ishizaka A: Genetic polymorphism of e-cadherin and COPD. Am J Respir Crit Care Med 2009, 179:A2999.

46. Kasahara DI, Williams AS, Benedito LA, Ranschr B, Kobzik L, Hug C, Shore SA: Role of the adiponectin binding protein, t-cadherin (cdh13), in pulmonaryt responses to subacute ozone. PLoS One 2013, 8:e65829.

47. Takeuchi T, Misaki A, Fujita J, Sonobe H, Ohtsuki Y: T-cadherin (cdh13, $\mathrm{h}$-cadherin) expression downtregulated surfactant protein $\mathrm{d}$ in bronchioloalveolar cells. Virchows Arch 2001, 438:370-375.

48. Faner R, Tal-Singer R, Riley JH, Celli B, Vestbo J, MacNee W, Bakke P, Calverley PM, Coxson H, Crim C, Edwards LD, Locantore N, Lomas DA, Miller BE, Rennard SI, Wouters EF, Yates JC, Silverman EK, Agusti A: Lessons from ECLIPSE: a review of COPD biomarkers. Thorax 2013, 69(7):666-672.

49. Aqusti A, Sin DD: Biomarkers in COPD. Clin Chest Med 2014, 35(1):131-141.

doi:10.1186/s12931-014-0127-9

Cite this article as: Carolan et al.: The association of plasma biomarkers with computed tomography-assessed emphysema phenotypes. Respiratory Research 2014 15:127.

\section{Submit your next manuscript to BioMed Central and take full advantage of:}

- Convenient online submission

- Thorough peer review

- No space constraints or color figure charges

- Immediate publication on acceptance

- Inclusion in PubMed, CAS, Scopus and Google Scholar

- Research which is freely available for redistribution 